\title{
Determinants of patient satisfaction with hospital health care in psychiatry: results based on the SATISPSY-22 questionnaire
}

This article was published in the following Dove Press journal:

Patient Preference and Adherence

24 October 2014

Number of times this article has been viewed

\section{Xavier Y Zendjidjian ${ }^{1,2}$ \\ Pascal Auquier' \\ Christophe Lançon ${ }^{1,3}$ \\ Anderson Loundou' \\ Nathalie Parola ${ }^{4}$ \\ Melanie Faugère ${ }^{3}$ \\ Laurent Boyer'}

'Aix-Marseille University, Public Health, Chronic Diseases and Quality of Life, Research Unit, Marseille, France; '2Department of Psychiatry, Inpatient Psychiatric Unit, La Conception University Hospital, Marseille, France; ${ }^{3}$ Department of Psychiatry, Psychiatric Public Sector 6, ${ }^{4}$ Department of Addictology, Day Hospital, Sainte-Marguerite University Hospital, Marseille, France

Correspondence: Xavier Y Zendjidjian EA 3279, Self-Perceived Health Assessment Research Unit, School of Medicine, La Timone University, I 3005 Marseille, France

$\mathrm{Tel}+3367678 \mathrm{I} 383$

$\mathrm{Fax}+33$ 49| 435 II5

Email xavier.zendjidjian@ap-hm.fr
Background: The aim of our study was to identify patient- and care-related factors that are associated with patients' satisfaction with psychiatric hospital care, using a specific, selfadministered questionnaire based exclusively on the patient's point of view: the Satisfaction with Psychiatry Care Questionnaire-22 (SATISPSY-22).

Methods: This cross-sectional study was conducted in the psychiatric departments of two French public university teaching hospitals. The data collected included sociodemographic information, clinical characteristics, care characteristics, and the SATISPSY-22. A multivariate analysis using multiple linear regressions was performed to determine the variables potentially associated with satisfaction levels.

Results: Two hundred seventy patients were enrolled in our study. Only one moderate association was found between satisfaction and sociodemographic characteristics: the personal experience dimension with age $(\beta=0.15)$. Clinical improvement was moderately associated with higher global satisfaction $(\beta=-0.15)$, higher satisfaction with quality of care $(\beta=-0.19)$, and higher satisfaction with food $(\beta=-0.18)$. Stronger associations with satisfaction were found for care characteristics, particularly the therapeutic alliance with all of the satisfaction dimensions $(\beta, 0.20-0.43)$ except food, and for seclusion with global satisfaction $(\beta=-0.33)$ and personal experience $(\beta=-0.32)$. Patients with previous hospitalization also had a higher level of satisfaction with quality of care compared with patients who were admitted for the first time $(\beta=-0.15)$.

Conclusion: This study has identified a number of potential determinants of satisfaction. The therapeutic relationship and seclusion were the most important features associated with a patient's satisfaction. These factors might be amenable through intervention, which, in turn, might be expected to improve satisfaction, patients' management, and health outcomes in psychiatric hospitals.

Keywords: satisfaction, determinants, inpatient, hospital, psychiatry

\section{Introduction}

Patients' reported outcomes (PROs), including measures of quality of life, disability, and satisfaction, have gained increasing attention in mental health services during the last decades. ${ }^{1-3}$ Although the symptomatic evaluations remain of great importance in the treatment of mental disorders, it is now well recognized that they do not reflect all of the facets patients consider important in their life..$^{4-6}$ It is currently established that patients' views should supplement the usual indicators of quality in health care, ${ }^{7-9}$ and patient satisfaction has become a significant contributing outcome in the assessment and improvement of health care quality for hospitalized populations. ${ }^{10}$ Satisfaction with inpatient care should predict future behaviors, including treatment adherence, intent to return for care and promptness of follow-up, and continuity of 
outpatient care. ${ }^{11-15}$ More satisfied patients have better health outcomes after hospital discharge,${ }^{16}$ which reduces the likelihood of rehospitalization. ${ }^{14}$ Understanding the determinants of satisfaction is of importance when developing effective interventions that can improve patient satisfaction, which may, in turn, improve other health-related outcomes and reduce rehospitalization. ${ }^{17-19}$

Numerous studies have investigated the determinants of inpatient satisfaction with care. Despite frequent contradiction among the findings of these studies, there is a general agreement that satisfaction is predicted by factors that can be categorized as endogenous (eg, structure, process, and outcome of care) or exogenous (eg, patients' characteristics) to the care received. ${ }^{18,20-22}$ Recent studies have even suggested that patient characteristics, such as age, health status, and education, may be the most important determinants of patient satisfaction. ${ }^{20,23}$ Several limitations of these previous studies should, however, be considered. First, the majority of these studies focused on medical or surgical care; they rarely focused on inpatient psychiatric care. ${ }^{24-31}$ Most of the studies on psychiatric care did not examine the concomitant effect of patient-related (ie, sociodemographic and clinical characteristics) and care-related factors on satisfaction. Moreover, the satisfaction questionnaires used in these studies (ie, generic questionnaires that are most often elaborated for patients with medical or surgical care or specific questionnaires derived directly from the literature or experts) can be criticized. ${ }^{1,32}$ Because patients with mental disorders have specific and different expectations about their hospitalization, generic instruments may not be relevant in psychiatry. ${ }^{19}$ It is also generally agreed that the content of specific measures should be derived directly from patients' concerns and perceptions. ${ }^{33}$

The aim of our study was therefore to identify the patientand care-related factors that are associated with patients' satisfaction with psychiatric hospital care, using a specific, self-administered questionnaire based exclusively on the patient's point of view: the Satisfaction with Psychiatry Care Questionnaire-22 (SATISPSY-22).

\section{Method}

\section{Study design and population}

This cross-sectional study was conducted in the psychiatric departments of two French public university teaching hospitals in Marseille (La Conception hospital and SainteMarguerite hospital) during a 3-month period. Eligible patients were adults who had been hospitalized for at least 24 hours. The patients were included in the study on their discharge day, regardless of their disorder or the length of their stay. Research assistants invited them to participate and explained the purpose of the study. The study was carried out in accordance with the principles of the Declaration of Helsinki, 6th revision. ${ }^{34}$ All subjects gave informed consent. The Ethics Committee (Commission Nationale de l'Informatique et des Libertés, France, no 909318v1) approved this study.

\section{Data collection}

The data collected included sociodemographic information such as age, sex, educational level, and marital status, as well as clinical characteristics such as diagnosis according to the International Statistical Classification of Diseases and Related Health Problems, Tenth Revision, severity of patient's illness at the time of discharge (Clinical Global Impression-Severity scale [CGI-S]), and how much the patient's illness improved since his or her entrance to the hospital (CGI-Improvement scale [CGI-I]). ${ }^{35}$ These two scales range from 1 (normal or very much improved) to 7 (among the most severely ill patients or very much worse). The study also considered the functioning of patients at the time of discharge (Global Assessment Functioning [GAF]). ${ }^{36}$ The GAF assigns a clinical judgment to the individual's overall functioning level (ie, psychological, social, and occupational/school functioning) and ranges from 0 (inadequate information) to 100 (superior functioning). All these assessments were made by a qualified mental health professional who was in charge of the patient.

Other data collected included characteristics such as length of hospitalization, hospitalization under constraint, seclusion, number of previous hospitalizations, and therapeutic relationships with the clinicians, measured using the 4-point ordinal Alliance Self-report ${ }^{37}$ (scores range from 11-44, with higher scores indicating a more positive alliance), as well as results of the satisfaction questionnaire.

The SATISPSY-22 is a specific, short, self-administered, multidimensional satisfaction questionnaire designed for people with mental disorders. ${ }^{38}$ It is composed of 22 items that describe six dimensions: satisfaction with staff (seven items), quality of care (five items), personal experience (four items), information (two items), activity (two items), and food (two items). The SATISPSY-22 also included a total score (index). All items are answered using an unbalanced 5-point Likert scale: "extremely less than expected," "worse than expected," "a little less than expected," "as expected," and "better than expected." For each individual, scores in each dimension are computed if at least half of the contributive items were answered. The score of each 
dimension is obtained by computing the mean of the item scores on the dimension. A global index score is computed by finding the mean of all of the dimension scores. All of the dimension scores and the index are linearly transformed and standardized on a $0-100$ scale $(0$, lowest satisfaction; 100 , highest satisfaction). Patients completed the SATISPSY-22 at the time of discharge.

\section{Statistical analyses}

Data were expressed as proportions or means and standard deviations.

Associations between satisfaction scores and the continuous variables (age, CGI-S, CGI-I, length of hospitalization, GAF, 4-point ordinal Alliance Scale) were analyzed using Spearman's correlation tests. Means-based comparisons of the SATISPSY-22 dimensions between various subgroups (sex, educational level, marital status, hospitalization under constraint, seclusion, number of previous hospitalizations, and psychiatric diagnosis) were calculated using MannWhitney tests.

Multivariate analyses using multiple linear regressions (simultaneous model) were then performed to determine which variables were potentially associated with satisfaction levels. The SATISPSY-22 index and each of its dimensions were considered separate dependent variables. The variables relevant to the models were selected from the bivariate SATISPSY-22 index analysis, based on a threshold $P$-value $\leq 0.20$. An additional variable was included in the models because of its sociodemographic interest (age). The final models incorporated the standardized $\beta$ coefficients, which represent a change in the standard deviation of the dependent variable (satisfaction) resulting from a onestandard-deviation change in the various independent variables. The independent variables with the higher standardized beta coefficients are those with a greater relative effect on satisfaction.

All of the tests were two-sided. Statistical significance was defined as $P<0.05$. The SPSS version 18.0 software package (SPSS Inc., Chicago, IL, USA) was used to perform the statistical analyses.

\section{Results}

\section{Sample characteristics}

Of the 295 eligible patients, 270 (91.5\%) consecutive patients agreed to participate in the study. Nonparticipants did not differ according to sex, age, or educational level. The patient characteristics of the study sample are presented in Table 1.
Table I Sample characteristics $(\mathrm{N}=270)$

\begin{tabular}{|c|c|}
\hline Characteristics & $\mathbf{N}(\%)$ \\
\hline \multicolumn{2}{|l|}{ Sociodemographic characteristics } \\
\hline Sex ratio (men) & I38 (5I.I) \\
\hline Age in years, mean \pm standard deviation & $45.4 \pm 15.3$ \\
\hline \multicolumn{2}{|l|}{ Marital status } \\
\hline Couple & $81(30.5)$ \\
\hline Single & $185(69.5)$ \\
\hline \multicolumn{2}{|l|}{ Educational level } \\
\hline$\geq 12$ years (final year of high school & $95(37.1)$ \\
\hline \multicolumn{2}{|l|}{ or university level) } \\
\hline$<12$ years & $158(62.9)$ \\
\hline \multicolumn{2}{|l|}{ Care characteristics } \\
\hline \multicolumn{2}{|l|}{ Hospitalization under constraint } \\
\hline Yes & $47(17.7)$ \\
\hline No & $218(82.3)$ \\
\hline \multicolumn{2}{|l|}{ Seclusion } \\
\hline Yes & $27(10.2)$ \\
\hline No & $239(89.8)$ \\
\hline Length of hospitalization, median & $26(15-42)$ \\
\hline \multicolumn{2}{|l|}{ (interquartile range) } \\
\hline \multicolumn{2}{|l|}{ Number of hospitalizations } \\
\hline I & $72(28.5)$ \\
\hline$>1$ & $|8|(7 \mid .5)$ \\
\hline \multicolumn{2}{|l|}{ Clinical characteristics } \\
\hline CGI severity, mean \pm standard deviation* & $4.4 \pm 1.2$ \\
\hline CGI improvement, mean \pm standard deviation & $2.3 \pm 0.9$ \\
\hline GAF, mean \pm standard deviation ${ }^{\#}$ & $61.9 \pm 15.3$ \\
\hline \multicolumn{2}{|l|}{ Psychiatric diagnosis ${ }^{\ddagger}$} \\
\hline Schizophrenia & 91 (34.3) \\
\hline Mood disorders & $140(52.8)$ \\
\hline Other & $34(12.8)$ \\
\hline
\end{tabular}

Notes: *Clinical global impression. ${ }^{\#}$ Global assessment functioning. ${ }^{*}$ Psychiatric diagnosis defined by the International Statistical Classification of Diseases and Related Health Problems, Tenth Revision.

\section{Factors associated with satisfaction}

Bivariate and multivariate analysis results are reported in Tables 2 and 3.

In the bivariate analysis, the SATISPSY-22 index was positively associated with marital status (in couples, $P<0.001)$, hospitalization without constraint $(P=0.022)$, absence of seclusion $(P=0.001)$, a higher number of previous hospitalizations $(>1 ; P=0.050)$, a better therapeutic alliance $(P=0.001)$, and better functioning $(P=0.030)$.

In the multivariate analysis, only one moderate association between satisfaction and a sociodemographic characteristic remained significant: personal experience with age ( $\beta=0.15)$. Regarding clinical characteristics, higher CGI improvement was moderately associated with higher global satisfaction $(\beta=-0.15)$, higher satisfaction for quality of care $(\beta=-0.19)$, and higher satisfaction for food $(\beta=-0.18)$. The link found in the bivariate analysis between satisfaction and GAF was no longer significant. Stronger associations with 
Table 2 Factors associated with the Satisfaction with Psychiatry Care Questionnaire-22 Index and dimension scores: bivariate analysis

\begin{tabular}{|c|c|c|}
\hline & $\begin{array}{l}\text { Satisfaction with Psychiatry Care } \\
\text { Questionnaire-22 Index, mean } \\
\text { (standard deviation) or } R^{*}\end{array}$ & $P$-value \\
\hline Sex & & 0.975 \\
\hline Male & $68.3(14.8)$ & \\
\hline Female & $68.4(15.0)$ & \\
\hline Educational level & & 0.833 \\
\hline$\geq 12$ years & $68.1(14.9)$ & \\
\hline$<12$ years & $68.6(15.1)$ & \\
\hline Marital status & & 0.001 \\
\hline Couple & $73.2(10.7)$ & \\
\hline Single & $66.7(15.9)$ & \\
\hline Hospitalization under constraint & & 0.022 \\
\hline Yes & $63.3(15.6)$ & \\
\hline No & $69.4(14.7)$ & \\
\hline Seclusion, mean & & 0.001 \\
\hline Yes & $57.9(16.3)$ & \\
\hline No & $69.5(14.4)$ & \\
\hline Number of previous hospitalizations & & 0.050 \\
\hline I & $67.2(15.4)$ & \\
\hline$>1$ & $71.6(14.0)$ & \\
\hline Psychiatric diagnoses & & 0.332 \\
\hline Schizophrenia & $67.0(14.0)$ & \\
\hline Mood disorders & $70.0(15.4)$ & \\
\hline Others & $67.0(15.2)$ & \\
\hline Age & 0.124 & 0.062 \\
\hline Clinical global impression severity & -0.042 & 0.528 \\
\hline Clinical global impression improvement & -0.111 & 0.098 \\
\hline Length of hospitalization & 0.000 & 0.995 \\
\hline 4-point ordinal Alliance Scale & 0.499 & 0.001 \\
\hline Global assessment functioning & 0.145 & 0.030 \\
\hline
\end{tabular}

Note: $* R$, Spearman's correlation coefficient.

satisfaction were found for care characteristics, particularly for the therapeutic alliance with all of the satisfaction dimensions ( $\beta, 0.20-0.43)$ except food, and for seclusion with global satisfaction $(\beta=-0.33)$ and personal experience $(\beta=-0.32)$. Patients with previous hospitalization also had a higher level of satisfaction with quality of care than did patients who were admitted for the first time $(\beta=-0.15)$. The $R$-squared (ie, the proportion of explained variance) was globally low for each multivariate model (ranging from 0.03 for the food dimension to 0.30 for the index).

\section{Discussion}

This study investigated inpatient- and care-related factors that are associated with satisfaction with psychiatric hospitals. To our knowledge, no study has described these links using both inpatient- and care-related factors and a specific, multidimensional satisfaction questionnaire based exclusively on the patient's point of view, such as the SATISPSY $-22 .{ }^{38}$
The first important finding of our study is that inpatientand care-related factors do not interact consistently with satisfaction, with significant variations arising depending on the satisfaction dimensions of the SATISPSY-22. Our multidimensional analysis of satisfaction using the SATISPSY-22 may explain some contradictory results from previous studies. ${ }^{24-31}$ Using a multidimensional questionnaire based on patients' points of view, such as the SATISPSY-22, is most likely more informative and relevant compared with other satisfaction instruments that are commonly used in psychiatry. Hospitalized psychiatric patients were fully involved in the process of item generation, selection, and validation of the SATISPSY-22. As a consequence, its content encompasses experiences that hold great importance to patients and is substantially different from other satisfaction instruments, which are primarily based on literature/expert opinions. ${ }^{1}$ In our study, the dimensions of the SATISPSY-22 that were similar to those of other instruments, such as the staff, information, and food dimensions, were less informative than the 
Table 3 Factors associated with Satisfaction with Psychiatry Care Questionnaire-22 Index and dimensions scores: multivariate analysis

\begin{tabular}{|c|c|c|c|c|c|c|c|}
\hline Characteristic & $\begin{array}{l}\text { Satisfaction with } \\
\text { Psychiatry Care } \\
\text { Questionnaire-22 } \\
\text { Index } \beta^{\#}\end{array}$ & Staff $\beta$ & $\begin{array}{l}\text { Quality } \\
\text { of care } \beta\end{array}$ & $\begin{array}{l}\text { Personal } \\
\text { experience } \beta\end{array}$ & Information $\beta$ & Activity $\beta$ & Food $\beta$ \\
\hline Sex & 0.011 & -0.004 & -0.072 & 0.081 & -0.010 & -0.020 & 0.114 \\
\hline Educational level & - & - & - & - & - & - & - \\
\hline Marital status & 0.047 & 0.013 & -0.077 & 0.060 & 0.102 & 0.039 & -0.081 \\
\hline $\begin{array}{l}\text { Hospitalization under } \\
\text { constraint }\end{array}$ & 0.106 & 0.033 & -0.033 & 0.044 & -0.024 & -0.013 & 0.015 \\
\hline Seclusion, mean & $-0.330 * *$ & -0.112 & -0.069 & $-0.316 * *$ & -0.144 & -0.097 & -0.094 \\
\hline $\begin{array}{l}\text { Number of previous } \\
\text { hospitalizations }\end{array}$ & -0.109 & -0.133 & $-0.145 *$ & -0.007 & -0.115 & -0.093 & -0.046 \\
\hline Psychiatric diagnoses & - & - & - & - & - & - & - \\
\hline Age & 0.062 & -0.052 & -0.004 & $0.147^{*}$ & -0.113 & 0.108 & 0.068 \\
\hline $\begin{array}{l}\text { Clinical global } \\
\text { impression severity }\end{array}$ & - & - & - & - & - & - & - \\
\hline $\begin{array}{l}\text { Clinical global } \\
\text { impression improvement }\end{array}$ & $-0.147 *$ & -0.108 & $-0.188 *$ & -0.036 & -0.077 & -0.046 & $-0.178 *$ \\
\hline Length of hospitalization & - & - & - & - & - & - & - \\
\hline $\begin{array}{l}\text { 4-point ordinal Alliance } \\
\text { Scale }\end{array}$ & $0.424 * *$ & $0.346 * *$ & $0.406 * *$ & $0.202 *$ & $0.233 * *$ & $0.264 * *$ & 0.104 \\
\hline $\begin{array}{l}\text { Global assessment } \\
\text { functioning }\end{array}$ & 0.014 & 0.052 & 0.074 & 0.056 & -0.005 & 0.106 & -0.102 \\
\hline $\begin{array}{l}R^{2} \text { (proportion of } \\
\text { explained variance) }\end{array}$ & 0.298 & 0.154 & 0.252 & 0.132 & 0.092 & 0.107 & 0.025 \\
\hline
\end{tabular}

Notes: ${ }^{*} \beta$, standardized beta coefficient $(\beta$ represents a change in the standard deviation in the satisfaction score resulting from a one standard deviation change in the independent variable). Bold values: $* P<0.05$; $* * P<0.0$ I.

more specific dimensions of hospitalized psychiatric patients, such as quality of care and personal experience. These findings suggest that the different facets of satisfaction should be assessed using patient-based questionnaires to fully guide the development of specific interventions that are intended to improve satisfaction.

Our study identified notable determinants of satisfaction that may assist mental health professionals in improving clinical outcomes related to satisfaction.

First, the therapeutic relationship was the most important and constant feature associated with a patient's satisfaction, thus confirming the central role of relationships in the patient experience. ${ }^{39}$ The 4-point ordinal Alliance Scale score, including drug-taking aspects and relationships with clinicians, was positively associated with all of the dimensions of the SATISPSY-22 except food. The quality of the therapeutic relationship has been reported in previous studies as being closely linked to satisfaction ${ }^{40,41}$ and is well-known as being determinant of illness course, attitude toward medication, and outcome of care. ${ }^{42-45}$ Emphasis should thus be placed on developing interventions that address barriers to these positive relationships, particularly ineffective and negative communication and a lack of trust. ${ }^{39}$ The use of coercion and constraint has also been described as an important determinant of satisfaction via its negative effect on the therapeutic relationship. ${ }^{39}$ Confirming this description, hospitalization under constraint was significant in the bivariate analysis, but it was not significant in the multivariate analysis after adjusting for the therapeutic relationship. This finding seems to confirm that the negative effect of constraint on satisfaction is most likely mediated by the therapeutic relationship. Moreover, a better understanding of the link between satisfaction and the therapeutic relationship seems necessary for some particularly difficult-to-treat populations (eg, patients with severe symptoms, long hospital stays, a high number of admissions, or younger-age patients) who are more likely to experience perceived coercion or restraint. ${ }^{22,46-49}$

The second most important feature associated with patient's satisfaction (only for the personal experience dimension) was seclusion, confirming findings of previous studies that reported seclusion and, more globally, staffpatient disagreement as being significantly associated with a lower satisfaction level. ${ }^{21,28,50,51}$ Contrary to the results for hospitalization under constraint, seclusion remained significant in the multivariate analysis, suggesting that seclusion has a negative effect on satisfaction that is not based on the 
therapeutic relationship. Despite advances in our knowledge and understanding of mental illness, seclusion continues to be widely used as a treatment option for a number of patients. Attention to the specific needs of patients in seclusion may help reduce the punitive connotations linked to this practice. ${ }^{52}$ Psychoeducational approaches and high transparency when applying coercive practices could improve patients' appreciation for these procedures. ${ }^{53}$ However, these approaches should not only provide patients with the opportunity to understand why the seclusion occurred and to restore their confidence with the staff but also act as a means for overcoming the negative effects and emotional effect related to these practices. ${ }^{52}$ In addition, it appears that the use of seclusion in care units is largely influenced by organizational factors that may have the potential for quality improvement. ${ }^{54}$ Hence, interventions to reduce the use of seclusion, restraint, and involuntary medication should also consider organizational and environmental factors. ${ }^{55}$

Another interesting result of our study concerns the association between the clinical characteristics of patients and satisfaction. We found that clinical improvement (CGI-I), as rated by the psychiatrist, was associated with higher satisfaction with quality of care, suggesting that the views of the patient and the professional are not completely independent, as occasionally reported in previous studies. ${ }^{8,56}$ If necessary, this finding also confirms that psychiatric patients' points of view concerning the quality of care are relevant and linked to the evolution of their health and treatment gains. However, the strength of this association was lower than it was for care characteristics (ie, the therapeutic relationship and seclusion). Although symptomatic improvement is important for patients, it is not the most important feature for them, confirming the need for clinicians to increase their attention to other aspects, rather than just focusing on symptoms. Unlike previous studies, ${ }^{22,57,58}$ our results showed that satisfaction was independent from the diagnosis categories and global functioning (GAF) or severity of psychopathology (CGI-S) on the day of discharge. One possible explanation for this discrepancy might be that clinical improvement (CGI-I), which previous studies did not consider to be a potential determinant, may have a confounding influence on the relationship between the indicators of the day of discharge predictors and satisfaction.

Finally, two determinants should be considered useful in interventions with target patients who are at risk for worse experiences. Younger patients and patients admitted for the first time tended to have lower satisfaction levels with personal experience and quality of care, respectively. These findings are in accordance with previous studies in which patient age was found to be the most frequent predictor of satisfaction in regard to sociodemographic factors, ${ }^{21}$ and first-time admission, especially in the case of involuntary admission, has been reported to be a traumatic and stressful experience that puts these patients at risk for poor health outcomes. ${ }^{59-61}$

\section{Limitations and perspectives}

This study had several limitations.

For example, this sample may not be representative of all hospitalized psychiatric patients. Indeed, our study was performed at two psychiatric hospitals in Marseille, France. Using more diverse and larger groups of patients is therefore required to confirm these results.

Second, our study used one specific type of satisfaction instrument, the SATISPSY-22, which is a questionnaire that is based exclusively on the patient's point of view. However, it would be interesting to determine whether our findings can be replicated with instruments that are based on other conceptual models and dimension constructs.

This study is also limited by the fact that it is crosssectional, rather than prospective, in design. No causal inference can be formally advanced, and our model should be interpreted from an associational point of view. Future studies are needed to establish whether the associations reported herein are longitudinally robust.

As in all self-reported satisfaction surveys, our study can be limited by a social desirability response bias (ie, patients may have reported greater satisfaction than they actually felt because they believed that positive comments are more acceptable).

Another limitation of the study is the distribution of the SATISPSY-22 at discharge. Another way to distribute the questionnaire could have been to give it to the patients at discharge and ask for them to return it later by mail. Although this way increases the reliability of the responses made by the patients, this approach may also decrease the response rate substantially.

Finally, despite the large numbers of determinants included in our analyses, the multivariate models explained between $3 \%$ and $30 \%$ of the explained variance, suggesting other important factors may influence the satisfaction of patients (eg, relationships with family, caregivers). Future studies should focus on identifying these factors.

\section{Conclusion}

This study has identified a number of potential determinants of satisfaction by using a specific, multidimensional satisfaction questionnaire that is based exclusively on patients' points of view for the first time. The therapeutic 
relationship and seclusion were the most important features associated with patient satisfaction. These factors might be amenable with intervention, which, in turn, might be expected to improve satisfaction, patient management, and health outcomes in psychiatric hospitals. The different facets of satisfaction, particularly the quality of care and personal experience dimensions, should be considered when developing specific interventions.

\section{Acknowledgments}

The authors are grateful to all of the patients for their participation in the study. This work was supported by institutional grants from the 2009 Appel Offre-Recherche Clinique Assistance Publique, Hôpitaux de Marseille. The sponsor of this research was Assistance Publique, Hôpitaux de Marseille, France, and its role was to control the appropriateness of ethical and legal considerations.

\section{Author contributions}

Conception and design were performed by XZ, PA, CL, and LB. Study coordination was performed by XZ. Inclusion and clinical data collection were performed by XZ, NP, and MF. Analysis of data was performed by $\mathrm{XZ}$ and $\mathrm{AL}$. Interpretation of data was performed by XZ, PA, and LB. Drafting and writing the manuscript was performed by XZ, PA, and LB. Revising the manuscript critically for important intellectual content was performed by XZ, PA, CL, AL, NP, MF, and LB (all the authors).

\section{Disclosure}

The authors report no conflicts of interest in this work.

\section{References}

1. Boyer L, Baumstarck-Barrau K, Cano N, et al. Assessment of psychiatric inpatient satisfaction: a systematic review of self-reported instruments. Eur Psychiatry. 2009;24(8):540-549.

2. Boyer L, Baumstarck K, Boucekine M, Blanc J, Lançon C, Auquier P. Measuring quality of life in patients with schizophrenia: an overview. Expert Rev Pharmacoecon Outcomes Res. 2013;13(3):343-349.

3. Baumstarck K, Boyer L, Boucekine M, Michel P, Pelletier J, Auquier P. Measuring the quality of life in patients with multiple sclerosis in clinical practice: a necessary challenge. Mult Scler Int. 2013;2013:524894.

4. Nair K, Dolovich L, Cassels A, et al. What patients want to know about their medications. Focus group study of patient and clinician perspectives. Can Fam Physician. 2002;48:104-110.

5. Epstein KR, Laine C, Farber NJ, Nelson EC, Davidoff F. Patients' perceptions of office medical practice: judging quality through the patients' eyes. Am J Med Qual. 1996;11(2):73-80.

6. Laine C, Davidoff F, Lewis CE, et al. Important elements of outpatient care: a comparison of patients' and physicians' opinions. Ann Intern Med. 1996;125(8):640-645.

7. Laine $C$, Davidoff F. Patient-centered medicine. A professional evolution. JAMA. 1996;275(2):152-156.

8. Barlési F, Boyer L, Doddoli C, Antoniotti S, Thomas P, Auquier P. The place of patient satisfaction in quality assessment of lung cancer thoracic surgery. Chest. 2005;128(5):3475-3481.
9. Boyer L, Lançon C, Baumstarck K, Parola N, Berbis J, Auquier P. Evaluating the impact of a quality of life assessment with feedback to clinicians in patients with schizophrenia: randomised controlled trial. Br J Psychiatry. 2013;202(6):447-453.

10. Antoniotti S, Baumstarck-Barrau K, Siméoni MC, et al. Validation of a French hospitalized patients' satisfaction questionnaire: the QSH-45. Int J Qual Health Care. 2009;21(4):243-252.

11. Cleary PD, McNeil BJ. Patient satisfaction as an indicator of quality care. Inquiry. 1988;25(1):25-36.

12. Fitzpatrick R. Surveys of patients satisfaction: I - Important general considerations. BMJ. 1991;302(6781):887-889.

13. Ware JE Jr, Davies AR. Behavioral consequences of consumer dissatisfaction with medical care. Eval Program Plann. 1983;6(3-4):291-297.

14. Druss BG, Rosenheck RA, Stolar M. Patient satisfaction and administrative measures as indicators of the quality of mental health care. Psychiatr Serv. 1999;50(8):1053-1058.

15. Bowersox NW, Bohnert AS, Ganoczy D, Pfeiffer PN. Inpatient psychiatric care experience and its relationship to posthospitalization treatment participation. Psychiatr Serv. 2013;64(6):554-562.

16. Chue $P$. The relationship between patient satisfaction and treatment outcomes in schizophrenia. J Psychopharmacol. 2006;20(6)(suppl): 38-56.

17. Becker T, Knapp M, Knudsen HC, et al. Aims, outcome measures, study sites and patient sample. EPSILON Study 1. European Psychiatric Services: Inputs Linked to Outcome Domains and Needs. Br J Psychiatry Suppl. 2000;(39):s1-s7.

18. Jackson JL, Chamberlin J, Kroenke K. Predictors of patient satisfaction. Soc Sci Med. 2001;52(4):609-620.

19. Bjørngaard JH, Ruud T, Friis S. The impact of mental illness on patient satisfaction with the therapeutic relationship: a multilevel analysis. Soc Psychiatry Psychiatr Epidemiol. 2007;42(10):803-809.

20. Xiao H, Barber JP. The effect of perceived health status on patient satisfaction. Value Health. 2008;11(4):719-725.

21. Nguyen Thi PL, Briançon S, Empereur F, Guillemin F. Factors determining inpatient satisfaction with care. Soc Sci Med. 2002; 54(4):493-504.

22. Gebhardt S, Wolak AM, Huber MT. Patient satisfaction and clinical parameters in psychiatric inpatients - the prevailing role of symptom severity and pharmacologic disturbances. Compr Psychiatry. 2013; 54(1):53-60.

23. Hekkert KD, Cihangir S, Kleefstra SM, van den Berg B, Kool RB. Patient satisfaction revisited: a multilevel approach. Soc Sci Med. 2009; 69(1):68-75.

24. Berghofer G, Lang A, Henkel H, Schmidl F, Rudas S, Schmitz M. Satisfaction of inpatients and outpatients with staff, environment, and other patients. Psychiatr Serv. 2001;52(1):104-106.

25. Holcomb WR, Parker JC, Leong GB, Thiele J, Higdon J. Customer satisfaction and self-reported treatment outcomes among psychiatric inpatients. Psychiatr Serv. 1998;49(7):929-934.

26. Soergaard KW, Nivison M, Hansen V, Oeiesvold T. Treatment needs and acknowledgement of illness - importance for satisfaction with psychiatric inpatient treatment. BMC Health Serv Res. 2008;8(1):103.

27. Prince JD. Determinants of care satisfaction among inpatients with schizophrenia. Community Ment Health J. 2006;42(2):189-196.

28. Svensson B, Hansson L. Patient satisfaction with inpatient psychiatric care. The influence of personality traits, diagnosis and perceived coercion. Acta Psychiatr Scand. 1994;90(5):379-384.

29. Boydell J, Morgan C, Dutta R, et al. Satisfaction with inpatient treatment for first-episode psychosis among different ethnic groups: a report from the UK AeSOP study. Int J Soc Psychiatry. 2012;58(1):98-105.

30. Hansson L. Patient satisfaction with in-hospital psychiatric care. A study of a 1-year population of patients hospitalized in a sectorized care organization. Eur Arch Psychiatry Neurol Sci. 1989;239(2): 93-100.

31. Shiva A, Haden SC, Brooks J. Psychiatric civil and forensic inpatient satisfaction with care: the impact of provider and recipient characteristics. Soc Psychiatry Psychiatr Epidemiol. 2009;44(11):979-987. 
32. Evans J, Rose D, Flach C, et al. VOICE: developing a new measure of service users' perceptions of inpatient care, using a participatory methodology. J Ment Health. 2012;21(1):57-71.

33. Avis M. Incorporating patients' voices in the audit process. Qual Health Care. 1997;6(2):86-91.

34. World Medical Association. World Medical Association Declaration of Helsinki Ethical Principles for Medical Research Involving Human Subjects. Edinburgh, UK: World Medical Assiciation; 2008. Available from: http://www.wma.net/en/30publications/10policies/b3/17c.pdf. Accessed: June 1, 2014.

35. Guy W. ECDEU Assessment Manual for Psychopharmacology. Rockville, MD: U.S. Department of Health, Education, and Welfare; 1976.

36. Endicott J, Spitzer RL, Fleiss JL, Cohen J. The global assessment scale. A procedure for measuring overall severity of psychiatric disturbance. Arch Gen Psychiatry. 1976;33(6):766-771.

37. Misdrahi D, Verdoux H, Lançon C, Bayle F. The 4-Point ordinal Alliance Self-report: a self-report questionnaire for assessing therapeutic relationships in routine mental health. Compr Psychiatry. 2009;50(2): 181-185.

38. Zendjidjian XY, Auquier P, Lançon C, et al. The SATISPSY-22: development and validation of a French hospitalized patients' satisfaction questionnaire in psychiatry. Eur Psychiatry. Epub 2014 May 21.

39. Gilburt H, Rose D, Slade M. The importance of relationships in mental health care: a qualitative study of service users' experiences of psychiatric hospital admission in the UK. BMC Health Serv Res. 2008;8(1):92.

40. Ware NC, Tugenberg T, Dickey B. Practitioner relationships and quality of care for low-income persons with serious mental illness. Psychiatr Serv. 2004;55(5):555-559.

41. Sylvia LG, Hay A, Ostacher MJ, et al. Association between therapeutic alliance, care satisfaction, and pharmacological adherence in bipolar disorder. J Clin Psychopharmacol. 2013;33(3):343-350.

42. Clarkin JF, Hurt SW, Crilly JL. Therapeutic alliance and hospital treatment outcome. Hosp Community Psychiatry. 1987;38(8):871-875.

43. Day JC, Bentall RP, Roberts C, et al. Attitudes toward antipsychotic medication: the impact of clinical variables and relationships with health professionals. Arch Gen Psychiatry. 2005;62(7):717-724.

44. Frank AF, Gunderson JG. The role of the therapeutic alliance in the treatment of schizophrenia. Relationship to course and outcome. Arch Gen Psychiatry. 1990;47(3):228-236.

45. Dassa D, Boyer L, Benoit M, Bourcet S, Raymondet P, Bottai T. Factors associated with medication non-adherence in patients suffering from schizophrenia: a cross-sectional study in a universal coverage healthcare system. Aust N Z J Psychiatry. 2010;44(10):921-928.

46. Knutzen M, Bjørkly S, Eidhammer G, et al. Mechanical and pharmacological restraints in acute psychiatric wards - why and how are they used? Psychiatry Res. 2013;209(1):91-97.

47. Knutzen M, Bjørkly S, Eidhammer G, et al. Characteristics of patients frequently subjected to pharmacological and mechanical restrainta register study in three Norwegian acute psychiatric wards. Psychiatry Res. 2014;215(1):127-133
48. O’Donoghue B, Roche E, Shannon S, Lyne J, Madigan K, Feeney L. Perceived coercion in voluntary hospital admission. Psychiatry Res. 2014;215(1):120-126.

49. Donnelly V, Lynch A, Mohan D, Kennedy HG. Working alliance, interpersonal trust and perceived coercion in mental health review hearings. Int J Ment Health Syst. 2011;5(1):29.

50. Lasalvia A, Bonetto C, Tansella M, Stefani B, Ruggeri M. Does staffpatient agreement on needs for care predict a better mental health outcome? A 4-year follow-up in a community service. Psychol Med. 2008;38(1):123-133.

51. Strauss JL, Zervakis JB, Stechuchak KM, et al. Adverse impact of coercive treatments on psychiatric inpatients' satisfaction with care. Community Ment Health J. 2013;49(4):457-465.

52. Cano N, Boyer L, Garnier C, et al. L'isolement en psychiatrie: point de vue des patients et perspectives éthiques. [Patients' perception of seclusion in psychiatry: ethical perspectives]. Encephale. 2011; 37(suppl 1):S4-S10. French.

53. Jaeger M, Rossler W. Enhancement of outpatient treatment adherence: Patients' perceptions of coercion, fairness and effectiveness. Psychiatry Res. 2010;180(1):48-53.

54. Husum TL, Bjørngaard JH, Finset A, Ruud T. A cross-sectional prospective study of seclusion, restraint and involuntary medication in acute psychiatric wards: patient, staff and ward characteristics. BMC Health Serv Res. 2010;10(1):89.

55. van der Schaaf PS, Dusseldorp E, Keuning FM, Janssen WA, Noorthoorn EO. Impact of the physical environment of psychiatric wards on the use of seclusion. Br J Psychiatry. 2013;202(2):142-149.

56. Renzi C, Abeni D, Picardi A, et al. Factors associated with patient satisfaction with care among dermatological outpatients. Br J Dermatol. 2001;145(4):617-623.

57. Holikatti PC, Kar N, Mishra A, Shukla R, Swain SP, Kar S. A study on patient satisfaction with psychiatric services. Indian J Psychiatry. 2012;54(4):327-332.

58. Eklund M, Hansson L. Determinants of satisfaction with communitybased psychiatric services: a cross-sectional study among schizophrenia outpatients. Nord J Psychiatry. 2001;55(6):413-418.

59. Beattie N, Shannon C, Kavanagh M, Mulholland C. Predictors of PTSD symptoms in response to psychosis and psychiatric admission. J Nerv Ment Dis. 2009;197(1):56-60.

60. Fennig S, Rabinowitz J, Fennig S. Involuntary first admission of patients with schizophrenia as a predictor of future admissions. Psychiatr Serv. 1999;50(8):1049-1052.

61. Levine SZ. Population-based examination of the relationship between type of first admission for schizophrenia and outcomes. Psychiatr Serv. 2008;59(12):1470-1473.
Patient Preference and Adherence

\section{Publish your work in this journal}

Patient Preference and Adherence is an international, peer-reviewed, open access journal that focuses on the growing importance of patient preference and adherence throughout the therapeutic continuum. Patient satisfaction, acceptability, quality of life, compliance, persistence and their role in developing new therapeutic modalities and compounds to optimize

\section{Dovepress}

clinical outcomes for existing disease states are major areas of interest for the journal. This journal has been accepted for indexing on PubMed Central. The manuscript management system is completely online and includes a very quick and fair peer-review system, which is all easy to use. Visit http://www. dovepress.com/testimonials.php to read real quotes from published authors. 